\title{
Some aspects of the influence of the vertical wind speed gradient on the blade aerodynamics loads in high class wind generators
}

\author{
Julian Genov ${ }^{1, *}$ \\ ${ }^{1}$ Technical University of Sofia, Department of Mechanics, 8 K1. Ohridski Blvd., 1000 Sofia, Bulgaria
}

\begin{abstract}
The powerful wind generators, producing electric power on the order of megawatts are with impressive sizes. The studies on the interaction between the air flow and the wind turbine usually assume the airflow as homogeneous in vertical direction. While for smaller wind turbines this assumption does not lead to significant inaccuracies, for powerful generators the vertical gradient of the wind velocity causes a dependence of the aerodynamic interaction from the angle of rotation of the propeller and leads to a significant cyclic variability of the forces and moments acting on the blades, even for a flow considered as stationary in time. The study of this problem is important for strength loads and fatigue calculations as well as for an implementation of an individual pitch-control of the blades, which could allow a synthesis of a regulation depending on the angular position of the turbine. This could contribute to higher performance and higher reliability.
\end{abstract}

\section{Vertical distribution of wind speed}

The change of the wind speed in the vertical direction depends on a number of factors such as: the degree of stability which depends of the vertical convection processes, the turbulence of the flow, the extent of its thrust, atmospheric pressure, the nature of the terrain and the presence of bulkheads with their characteristics, etc. From the basically used two representations for this distribution, which are based on power and logarithmic functional dependences [1], in the present study is preferred the logarithmic model, derived from Prandtl's mixing length theory and which is based on physical and meteorological studies and more detailed takes into an account the factors noted above. The dependence formula is:

$$
v_{\infty}(z)=\frac{V^{*}}{k}\left[\ln \left(\frac{z-d}{z_{0}}\right)-\psi\left(z, z_{0}, L\right)\right], \mathrm{m} / \mathrm{s}
$$

where: $v^{*}=\sqrt{\tau_{s} / \rho}, \mathrm{m} / \mathrm{s}-$ shear (friction) velocity of the air flow, that describes shear-related motion of vertical transference of unit mass air due to the turbulence [2];

$\tau_{s}, \mathrm{~Pa}$ - shear stress of flow;

$\rho=p(z) M g / R T(z), \mathrm{kg} / \mathrm{m}^{3}$ - mass density, depending according the Clapeyron's law from temperature and altitude;

$p(z)=p_{0}\left(\frac{T(z)}{T_{0}}\right)^{\frac{g M_{g}}{R h_{t}}}, \mathrm{~Pa}$ - atmospheric pressure at level $z ;$ $p_{0}$ - atmospheric pressure at the zero level (for sea level $\left.p_{0}=101325 \mathrm{~Pa}\right)$;

$T_{0}, \mathrm{~K}$ - temperature at the zero level,

$h_{t}$ - dry air adiabatic lapse rate (temperature gradient with average value $0,0065 \mathrm{~K} / \mathrm{m}$ ),

$g=9,81 \mathrm{~m} / \mathrm{s}^{2}-$ gravitational acceleration,
$R=8,31447 \mathrm{~J} /(\mathrm{mol} \mathrm{K})$ - universal gas constant, $M_{g}-$ molar mass $(0,02896 \mathrm{~kg} / \mathrm{mol}$ for dry air $)$, $T(z)=T_{0}-h_{t} z, \mathrm{~K}-$ temperature at height $z$; $k \in[0,35 \div 0,42]$ von Kármán constant for the logarithmic distribution (the best estimate for the von Kármán constant for turbulent flow is found to be 0,4 [3]);

$d$-zero-plan displacement, define the height at which the mean velocity is zero due to large obstacles;

$z_{0}$ - aerodynamic roughness length is a corrective measure to account for the effect of the roughness of a surface on wind flow.

Table 1. Values of the parameters considering the influence of unevenness on the ground.

\begin{tabular}{|l|c|c|}
\hline Ground surface condition & $d, \mathrm{~m}$ & $z 0, \mathrm{~m}$ \\
\hline Water surface & 0,009 & 0,002 \\
\hline Marshy or snowy without plants and obstacles & 0,023 & 0,005 \\
\hline Flat grassy surface with small obstacles & 0,138 & 0,03 \\
\hline $\begin{array}{l}\text { Low crops occasional obstacles with a width to } \\
\text { high ratio } x / H>20\end{array}$ & 0,466 & 0,1 \\
\hline $\begin{array}{l}\text { Low crops occasional obstacles with a width to } \\
\text { high ratio } 15<x / H<20\end{array}$ & 1,175 & 0,25 \\
\hline Parkland, bushes, numerous obstacles & 2,235 & 0,5 \\
\hline Large forests, barriers suburbs of settlements & 4,467 & 1,0 \\
\hline City centres with high- and low- rise buildings & $>10$ & $>2$ \\
\hline
\end{tabular}

$$
\begin{aligned}
& \psi=\left\{\begin{array}{r}
\ln \left(\left(1+x^{2}\right)(1+x)^{2}\right)-2 \arctan (x)-0,5086, \\
\text { for } \zeta \in(-2 \div 0) \text { unstable flow } \\
\text { for } \zeta \geq 0 \text { stable flow }
\end{array}\right. \\
& \zeta=\frac{z}{L}, x=(1-16 \zeta)^{0,25}
\end{aligned}
$$

* Corresponding author: j_genov@mail.org 
wind shear - a criteria for fluid flow stability and turbulent kinetic energy;

$T_{v}=(1+0,61 w) T-$ virtual temperature. It is the temperature that a dry air would have if its pressure and density were equal to those of actual moist air;

$w$ - water mixing ratio, it is the ratio of moisture to the amount of dry air in the flow (often $w=3,5 \times 10^{-3}$ ), $\Phi_{H}=-h /\left(\rho c_{p}\right), \mathrm{Km} / \mathrm{s}-$ kinematic surface heat flux, $h=10,45-v_{\infty}+10 \sqrt{v_{\infty}} \mathrm{W} /\left(\mathrm{m}^{2} \mathrm{~K}\right)$ - heat transfer coefficient characterizes the convective heat transfer across a unit area;

$c_{p}$ - specific heat capacity, for the operating temperature range $c_{p} \approx 1005 \mathrm{~J} / \mathrm{kg} / \mathrm{K}$.

In the current study it is used the logarithmic wind distribution with the speed of $v_{\infty}\left(z_{t}\right)=11,4 \mathrm{~m} / \mathrm{s}$ at the height of the turbine axis $z_{t}=90 \mathrm{~m}$ with temperature of $298 \mathrm{~K}$ $\left(25^{\circ} \mathrm{C}\right)$ and grassy terrain. The values of the parameters and the calculated values according to the above dependencies are given in Table 2.

Table 2. Values of the parameters for the calculation of logarithmic wind speed distribution

\begin{tabular}{|c|c|c|c|c|c|}
\hline$L$ & $\Phi_{H}$ & $\rho$ & $T_{0}$ & $T_{v}$ & $c_{p}$ \\
\hline $\mathrm{m}$ & $\mathrm{Km} / \mathrm{s}$ & $\mathrm{kg} / \mathrm{m}^{3}$ & $\mathrm{~K}$ & $\mathrm{~K}$ & $\mathrm{~J} /(\mathrm{kgK})$ \\
\hline 59,9 & $-0,03$ & 1,23 & 298 & 290 & 1005 \\
\hline$k$ & $h$ & $\boldsymbol{v}^{*}$ & $\tau_{s}$ & $d$ & $z_{0}$ \\
\hline- & $\mathrm{W} /\left(\mathrm{m}^{2} \mathrm{~K}\right)$ & $\mathrm{m} / \mathrm{s}$ & $\mathrm{Pa}$ & $\mathrm{m}$ & $\mathrm{m}$ \\
\hline 0,4 & 33,09 & 0,28 & 0,097 & 0,138 & 0,03 \\
\hline
\end{tabular}

On Fig. 1 is shown the vertical wind speed distribution. As a result of the vertical gradient, the difference in the turbine disk speeds between the lower level $z=27 \mathrm{~m}$ and the upper $z=153 \mathrm{~m}$ (for a radius of the turbine disk $R=63 \mathrm{~m}$ ) is about $10 \mathrm{~m} / \mathrm{s}: 6,367 \div 15,98 \mathrm{~m} / \mathrm{s}$.

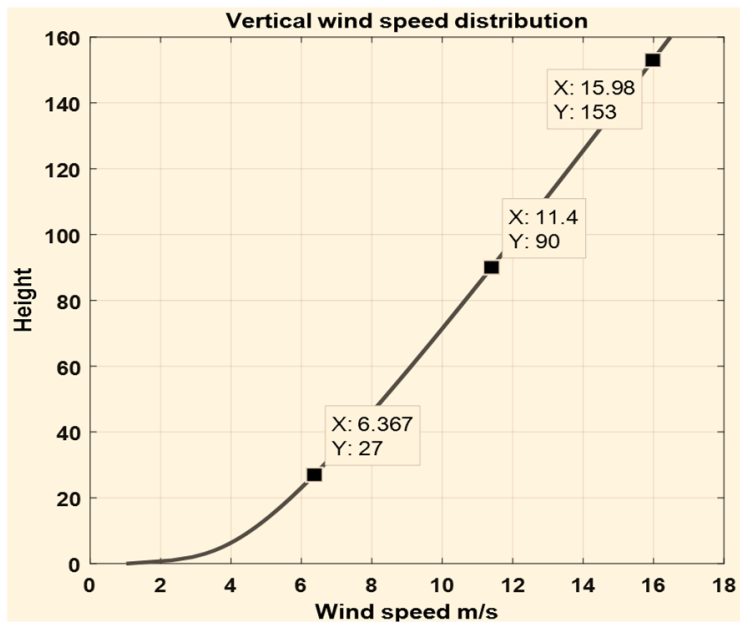

Fig. 1. Vertical distribution of wind speed.

\section{Mathematical model of the aerodynamic interaction between the wind and the turbine in considering the vertical wind velocity gradient}

The classical approach of the Blade element momentum (BEM) theory considers the fluid field as homogeneously [4-9]. In them for all blades, the dynamic interaction with the wind flow is the same and also does not depend on the azimuth angle which determines the position of each of them in the cross section - Fig. 2. But for the high class wind turbines, due to the inflow vertical speed gradient, it is observes significant different of the speed in the turbine disk and respectively causes different angles of attack for each of blades. For this reason the generated power and aerodynamic forces are function of the azimuth angle even for time-stationary wind flow. The common used methodology for calculation of induction coefficients [6] is not valid and is needs to be some refined.

In [10-15] some semi-analytical or numerical investigations in this or similar sense are made.

Many software realizations [16-26] in ANSYS Fluent, SolidWorks, Adams, Abacus, as well specialized products as FAST, AeroDyn, HAWC2 and others give also possibilities for modelling the aerodynamic loads in non homogenously wind field by using CFD computation, numerical-analytical calculations and approximations.

The aim of this investigation is to give one analytical model which among other approaches may be useful for the purposes of wind turbine control, loads and fatigue analysis, optimization, and others.

The elementary turbine disk area represented by the polar coordinates $r$ and $\gamma$ (azimuth angle) - Fig. 2, is:

$$
\Delta A_{d}(r, \gamma)=r \Delta r \Delta \gamma
$$

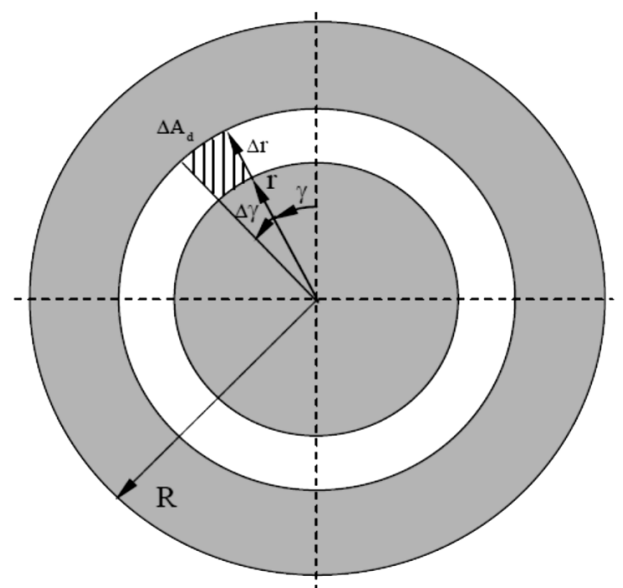

Fig. 2. Representation of the blade element area by polar frame of reference.

The dependencies for the axial thrust forces $F_{\text {Thrust }}$ and the torque $M_{w t}$ acting on that elementary area, on the corresponding ring of the turbine disk are:

$\Delta \mathrm{F}_{\text {Thrust }}\left(\varphi_{\mathrm{wt}}, \mathrm{r}, \gamma\right)=$

$$
\begin{gathered}
=\frac{\mathrm{d}}{\mathrm{dt}}\left[\Delta \mathrm{Q}_{\mathrm{m}}\left(\mathrm{v}_{\infty}(\mathrm{r}, \gamma)-\mathrm{v}_{\mathrm{w}}\left(\varphi_{\mathrm{wt}}, \mathrm{r}, \gamma\right)\right)\right] \mathrm{F}_{\mathrm{c}}\left(\varphi_{\mathrm{wt}}, \mathrm{r}\right)= \\
=\rho \Delta \mathrm{A}_{\mathrm{d}}(\mathrm{r}, \gamma) \mathrm{v}_{\mathrm{d}}\left(\varphi_{\mathrm{wt}}, \mathrm{r}, \gamma\right)\left(\mathrm{v}_{\infty}(\mathrm{r}, \gamma)-\mathrm{v}_{\mathrm{w}}(\mathrm{r}, \gamma)\right) \mathrm{F}_{\mathrm{c}}\left(\varphi_{\mathrm{wt}}, \mathrm{r}\right)= \\
=2 \rho \mathrm{a}\left(\varphi_{\mathrm{wt}}, \mathrm{r}\right)\left(1-\mathrm{a}\left(\varphi_{\mathrm{wt}}, \mathrm{r}\right)\right) \mathrm{F}_{\mathrm{c}}\left(\varphi_{\mathrm{wt}}, \mathrm{r}\right) \mathrm{rv}_{\infty}{ }^{2}(\mathrm{r}, \gamma) \Delta \gamma \Delta \mathrm{r} \\
\Delta F_{\text {Thrust }}\left(\varphi_{w t}, r\right)=\int_{\gamma=0}^{2 \pi} \Delta F_{\mathrm{Thrust}}\left(\varphi_{w t}, r, \gamma\right) d \gamma= \\
=2 \rho a\left(\varphi_{w t}, r\right)\left(1-a\left(\varphi_{w t}, r\right)\right) F_{c}\left(\varphi_{w t}, r\right) r \Delta r . \\
\cdot \int_{\gamma=0}^{2 \pi} v_{\infty}{ }^{2}(r, \gamma) d \gamma
\end{gathered}
$$




$$
\begin{gathered}
F_{\text {Thrust }}\left(\varphi_{w t}\right)=\int_{r=0}^{R} \Delta F_{\text {Thrust }}\left(\varphi_{w t}, r\right) d r= \\
=2 \rho \int_{r=0}^{R} a\left(\varphi_{w t}, r\right)\left(1-a\left(\varphi_{w t}, r\right)\right) F_{c}\left(\varphi_{w t}, r\right) r . \quad(2) \\
\cdot \int_{\gamma=0}^{2 \pi} v_{\infty}{ }^{2}(r, \gamma) d \gamma d r . \\
\Delta M_{w t}\left(\varphi_{w t}, r, \gamma\right)=F_{c}\left(r, \varphi_{w t}\right) \frac{d}{d t} \Delta I\left(\varphi_{w t}, r, \gamma\right) \omega_{d}\left(\varphi_{w t}, r\right)= \\
=\rho r v_{d}\left(\varphi_{w t}, r, \gamma\right) r^{2} \omega_{d}\left(\varphi_{w t}, r\right) F_{c}\left(\varphi_{w t}, r\right) \Delta r \Delta \gamma= \\
=2 \rho \omega_{w t} r^{3} a^{\prime}\left(\varphi_{w t}, r\right)\left(1-a\left(\varphi_{w t}, r\right)\right) v_{\infty}(r, \gamma) . \\
\cdot F_{c}\left(\varphi_{w t}, r\right) \Delta \gamma \Delta r, \\
\Delta M_{w t}\left(\varphi_{w t}, r\right)=\int_{\gamma=0}^{2 \pi} \Delta M_{w t}\left(\varphi_{w t}, r, \gamma\right) d \gamma= \\
=2 \rho \omega_{w t} a^{\prime}\left(\varphi_{w t}, r\right)\left(1-a\left(\varphi_{w t}, r\right)\right) F_{c}\left(\varphi_{w t}, r\right) r^{3} . \\
\cdot \int_{\gamma=0}^{2 \pi} v_{\infty}(r, \gamma) d \gamma \Delta r, \\
M_{w t}\left(\varphi_{w t}\right)=\int_{r=0}^{R} \Delta M_{w t}\left(\varphi_{w t}, r\right) d r= \\
=2 \rho \omega_{w t} \int_{r=0}^{R} a^{\prime}\left(\varphi_{w t}, r\right)\left(1-a\left(\varphi_{w t}, r\right)\right) F_{c}\left(\varphi_{w t}, r\right) r^{3} .(3) \\
\cdot \int_{\gamma=0}^{2 \pi} v_{\infty}(r, \gamma) d \gamma d r .
\end{gathered}
$$

where: $\varphi_{w t}$ - blade azimuth angle measurement from vertical position in counter clockwise direction;

$Q_{m}$ - mass flow rate;

$\rho$ - mass density;

$I$ - moment of inertia of the fluid in the turbine disk;

$v_{\infty}$ - inflow speed;

$v_{w}$ - flow speed in wake;

$v_{d}$ - flow speed in turbine disk;

$a=\left(v_{\infty}-v_{d}\right) / v_{\infty}-$ axial induction factor;

$a^{\prime}=0,5 \omega_{d} / \omega_{w t}-$ tangential induction factor;

$\omega_{d}$-angular velocity of the flow in the plane of the disk;

$F_{C}=F_{T L} F_{\text {Root }}-$ flow correction factor [5],

$F_{T L}=\frac{2}{\pi} \arccos \left(\mathrm{e}^{-\frac{\mathrm{N}}{2 \sin (\phi)}\left(\frac{\mathrm{R}}{\mathrm{r}}-1\right)}\right)-$ Tip-Loss Prandtl-Glauert correction;

$F_{\text {Root }}=\frac{2}{\pi} \arccos \left(e^{-\frac{N}{2 \sin (\phi)}\left(1-\frac{R_{H u b}}{r}\right)}\right)$ is a correction that considers the vortices at the blade's base around the turbine hub;

$N$ is the number of the blades; $R_{H u b}$ is the hub radius.

On Fig. 3 are shown angular, velocities and forces that describe the aerodynamic interaction for given blade cross-section.

$\beta\left(\varphi_{w t}, r\right)=\beta_{c}\left(\varphi_{w t}\right)+\beta_{0}(r)-$ pitch angle for the section;

$\beta_{0}(r)$ - constructive pitch angle for the section;

$\beta_{c}\left(\varphi_{w t}\right)$ - blade pitch angle set by the system for active pitch control;

$\phi\left(\varphi_{w t}, r\right)=\operatorname{arctg}\left(v_{d}\left(\varphi_{w t}, r\right) / v_{b}\left(\varphi_{w t}, r\right)\right) \quad-\quad$ inflow angle for the section;

$\alpha\left(\varphi_{w t}, r\right)=\phi\left(\varphi_{w t}, r\right)-\beta\left(\varphi_{w t}, r\right)$ - angle of attack.

$v_{b}\left(\varphi_{w t}, \mathrm{r}\right)-\mathrm{a}$ tangential component of the relative flow velocity for the section;

$v_{r e l}\left(\varphi_{w t}, \mathrm{r}\right)$ - relative (effective) flow velocity for the section;

$F_{\text {Torque }}\left(\varphi_{w t}, \mathrm{r}\right)$ - torque force;

$C_{\text {Torque }}, C_{\text {Thrust }}, C_{L}, C_{D}$ - torque, thrust, lift and drag coefficients of the section.

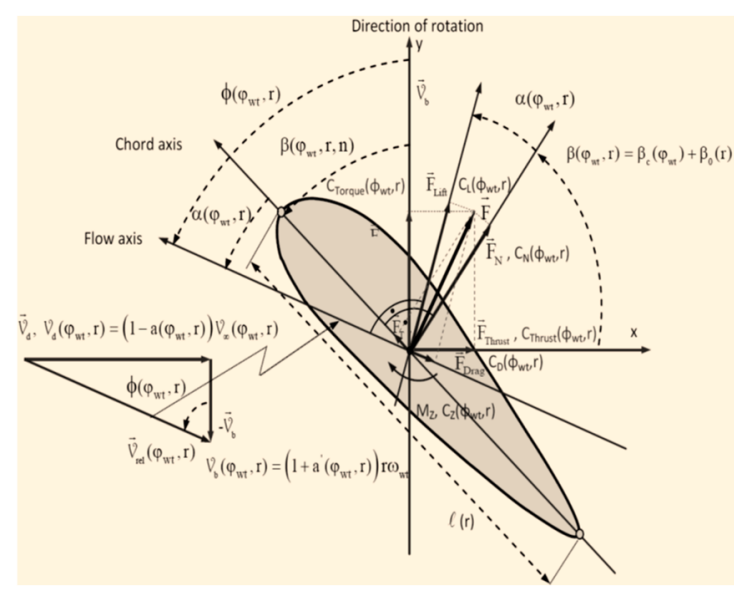

Fig. 3. Wind stream and induced forces acting on blade elements.

$$
\begin{aligned}
& \mid \begin{array}{l}
v_{b}\left(\varphi_{w t}, r\right)=r \omega_{w t}\left(1+a^{\prime}\left(\varphi_{w t}, r\right)\right) ; \\
v_{r e l}\left(\varphi_{w t}, r\right)=\frac{\left(1-a\left(\varphi_{w t}, r\right)\right)}{\sin \left(\phi\left(\varphi_{w t}, r\right)\right)} v_{\infty}\left(\varphi_{w t}, r\right) ; \\
\phi\left(\varphi_{w t}, r\right)=\operatorname{arctg}\left[\frac{\left(1-a\left(\varphi_{w t}, r\right)\right) v_{\infty}\left(\varphi_{w t}, r\right)}{r \omega_{w t r}\left(1+a^{\prime}\left(\varphi_{w t} r\right)\right)}\right]
\end{array} \\
& F_{\text {Thrust }}\left(\varphi_{w t}, r\right)=C_{\text {Thrust }}\left(\varphi_{w t}, r\right) F\left(\varphi_{w t}, r\right) \\
& F_{\text {Torque }}\left(\varphi_{w t}, r\right)=C_{\text {Torque }}\left(\varphi_{w t}, r\right) F\left(\varphi_{w t}, r\right)
\end{aligned}
$$

where:

$$
\begin{aligned}
& F\left(\varphi_{w t}, r\right)=0,5 \rho \ell_{T}(r) v_{r e l}{ }^{2}\left(\varphi_{w t}, r\right) F_{c}\left(\varphi_{w t}, r\right) ; \\
& C_{\text {Thrust }}\left(\varphi_{w t}, r\right)=C_{L}\left(\alpha\left(\varphi_{w t}, r\right)\right) \cos \left(\phi\left(\varphi_{w t}, r\right)\right)+ \\
& +C_{D}\left(\alpha\left(\varphi_{w t}, r\right)\right) \sin \left(\phi\left(\varphi_{w t}, r\right)\right) \text {; } \\
& C_{\text {Torque }}\left(\varphi_{w t}, r\right)=C_{L}\left(\alpha\left(\varphi_{w t}, r\right)\right) \sin \left(\phi\left(\varphi_{w t}, r\right)\right)- \\
& -C_{D}\left(\alpha\left(\varphi_{w t}, r\right)\right) \cos \left(\phi\left(\varphi_{w t}, r\right)\right) \text {; } \\
& \ell_{T}\left(\varphi_{w t}, r\right)=\ell(r) \cos \left(\beta\left(\varphi_{w t}, r\right)\right) .
\end{aligned}
$$

For the blade it is obtain:

$$
\mid \begin{aligned}
& a\left(\varphi_{w t}, r\right)=\frac{K\left(\varphi_{w t}, r\right)}{1+K\left(\varphi_{w t}, r\right)} \\
& a^{\prime}\left(\varphi_{w t}, r\right)=\frac{\omega_{d}\left(\varphi_{w t}, r\right)}{2 \omega_{w t}}=\frac{K_{\text {Torque }}\left(\varphi_{w t}, r\right)}{\tilde{\lambda}(r) K_{\text {Thrust }}\left(\varphi_{w t}, r\right)} a\left(\varphi_{w t}, r\right)
\end{aligned}
$$

where: $K\left(\varphi_{w t}, r\right)=\frac{\ell_{T}\left(\varphi_{w t}, r\right)}{4 r \int_{\gamma=0}^{2 \pi} \mathrm{v}_{\infty}^{2}(r, \gamma) d \gamma} K_{\text {Thrust }}\left(\varphi_{w t}, r\right)$,

$$
\tilde{\lambda}(r)=r \omega_{w t} \int_{\gamma=0}^{2 \pi} \mathrm{V}_{\infty}(r, \gamma) d \gamma / \int_{\gamma=0}^{2 \pi} \mathrm{V}_{\infty}{ }^{2}(r, \gamma) d \gamma .
$$

The iterative cycle for determining the aerodynamic characteristics for each blade element is:

- Set Initial values for the induction coefficients (most commonly);

- Calculate $\phi\left(\varphi_{i}, r\right)$ и $\alpha\left(\varphi_{i}, r\right), i=1, . . \mathrm{N}$ for the current values of $v_{\infty}\left(\varphi_{i}, r\right)$ and $\omega_{w t}$ (note for individual pitch $\operatorname{control} \beta_{c}\left(\varphi_{w t}\right) \Rightarrow \beta_{c}\left(\varphi_{i}\right)$;

- Determine the values of $C_{L}\left(\alpha\left(\varphi_{i}, r\right)\right)$ and $C_{D}\left(\alpha\left(\varphi_{i}, r\right)\right)$ via the calculated angles, $i=1, . . \mathrm{N}$, using experimentally obtained data for the corresponding airfoil;

- Calculate the corrections $F_{c}\left(\varphi_{i}, r\right), i=1, . . \mathrm{N}$;

- Obtain new values for the induction coefficients;

- Iterations continue until reaching a convergence. 


\section{Numerical results}

The obtained dependences are tested for prototype wind turbine NREL5MW [27] with reference operating wind speed $11,4 \mathrm{~m} / \mathrm{s}$ and angular speed of the turbine $12 \mathrm{rpm}$. The hub radius is $R_{h u b}=1,5 \mathrm{~m}$, the blade length is $L=61,5 \mathrm{~m}$, and the tower is with height of $H=90 \mathrm{~m}$.

The types of the airfoils along the blades, with their main characteristics and lift and drag coefficients as function of the angle of attack are given in [27].

Results of numerical simulation are shown on Figures 4 to 12 .

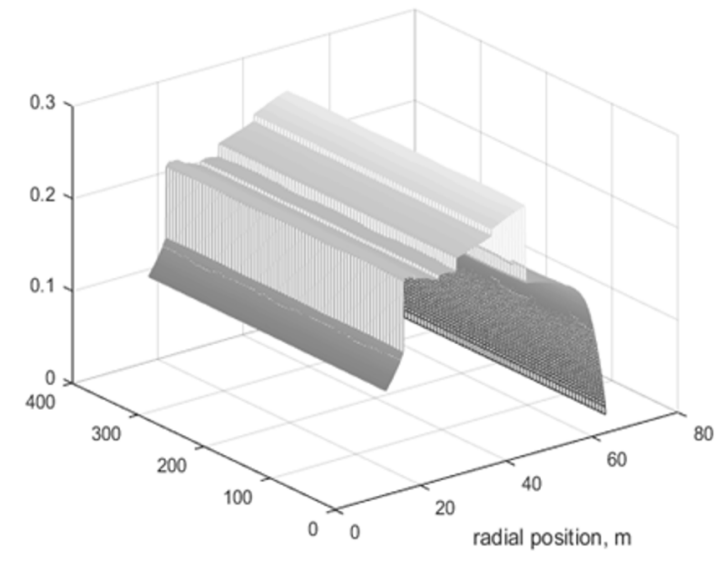

blade azimuth angle, deg

Fig. 4. Axial indication factor.

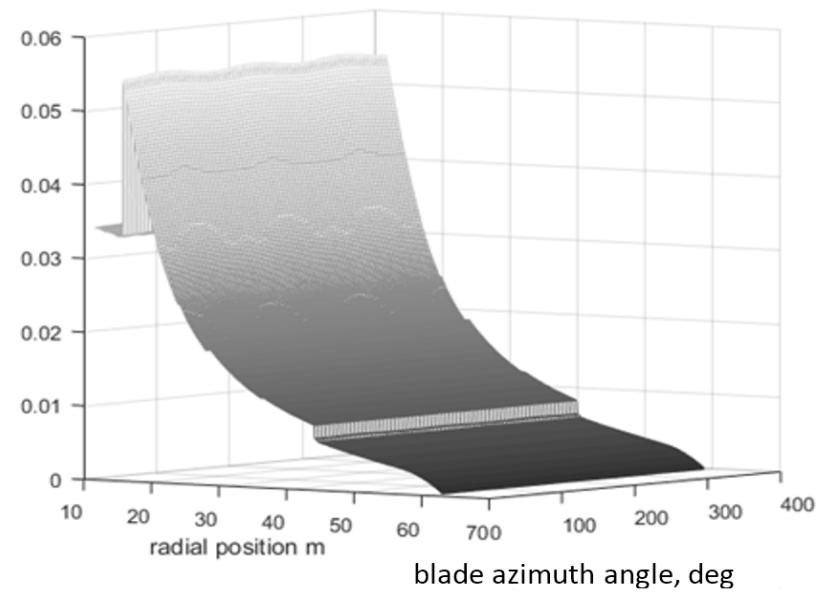

Fig. 5. Tangential induction factor.

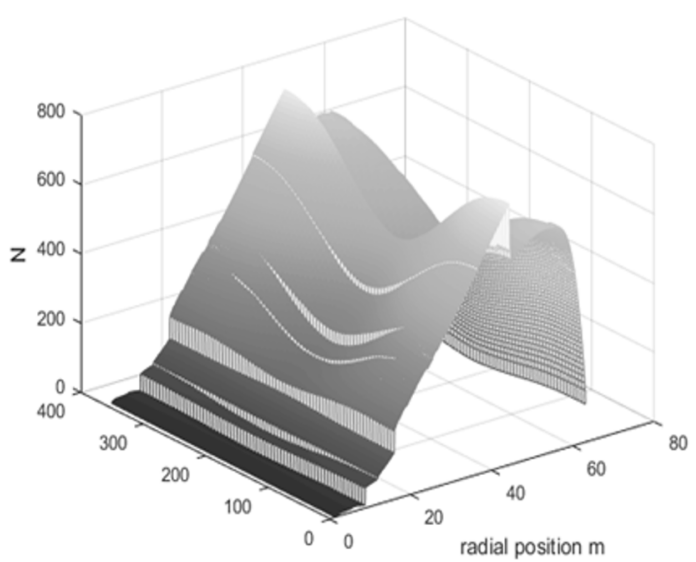

blade azimuth angle, deg

Fig. 6. Blade 1 Thrust forces distribution.

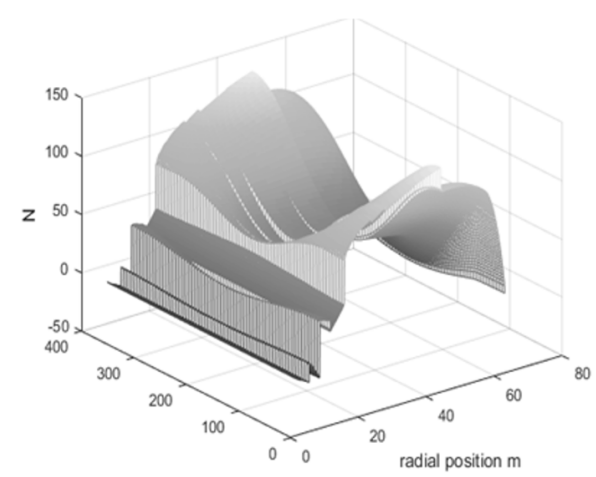

blade azimuth angle, deg

Fig. 7. Blade 1 Torque force distribution.

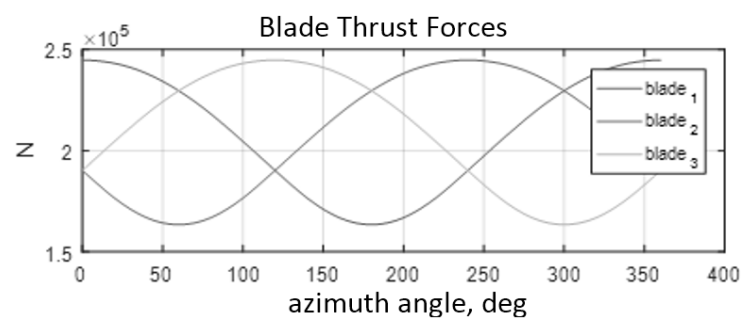

Fig. 8. Blade Thrust Forces.

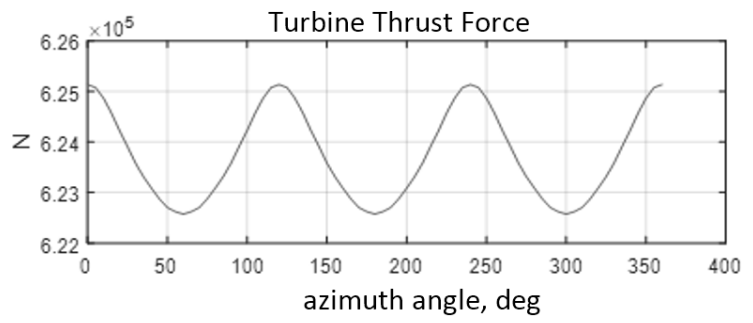

Fig. 9. Turbine Thrust Forces.

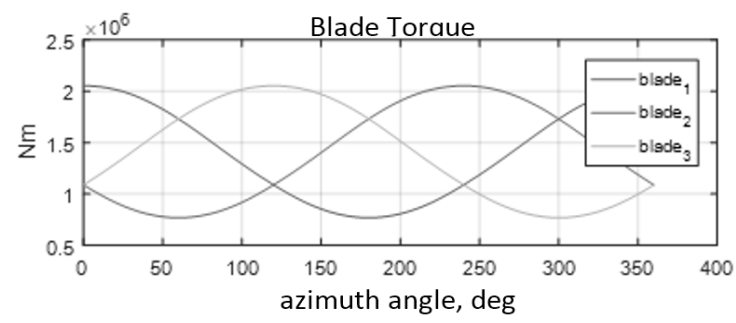

Fig. 10. Blade Torque.

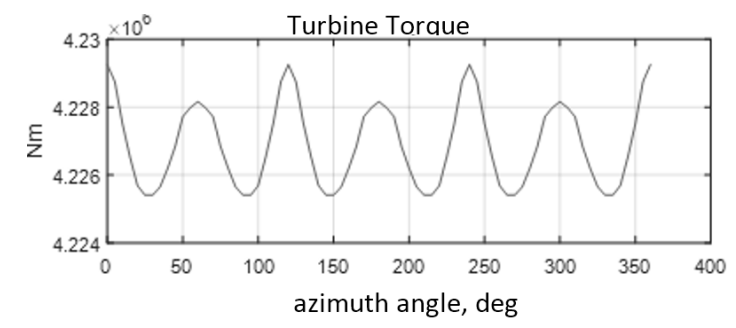

Fig. 11. Turbine Torque.

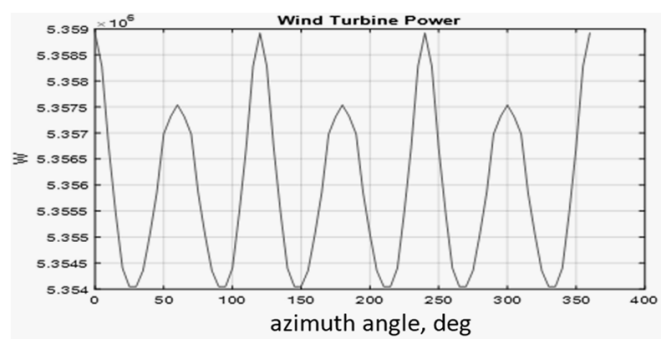

Fig. 12. Wind Turbine Power. 
The pulsations in the total axial force, torque and power generation have small amplitude with respect to their mean values: $F_{\text {Thrust }}=6,233 \pm 1,28 \mathrm{kN}, M_{w t}=4227$ $\pm 1,92 \mathrm{kNm}, P_{w t}=5,356 \mathrm{MW}$.

The calculations show that the variation in the load of the individual blades as a function of the angle of rotation due to the vertical gradient of the wind speed is very significant. For example for $F_{\text {Thrust }}$ amplitude is $40,6 \mathrm{kN}$ - nearly $20 \%$ of its mean value $\tilde{F}_{\text {Thrust }}=208 \mathrm{kN}$.

These values are aggregated for the whole blade. For the some elements in the middle part of the blade they are significant bigger.

\section{Conclusion}

The publication presents the BEM Theory adaptation in cases when the vertical speed gradient of the wind flow must be taken into an account. In those cases the turbine blades have different aerodynamic interactions with the flow and the classical BEM approach is not accurate. Here is proposing the solution of this problem what is applied and verified for a prototype of high class.

\section{References}

1. L. Landberg, Meteorology for Wind Energy - An Introduction, (John Wiley \& Sons Ltd., 2016)

2. S. Smith, et al., Sea surface wind stress and drag coefficients: The hexos results, Boundary-Layer Meteorology, 60, 109-142 (1992)

3. Y. Zhang, J. Ma, Z. Cao, The Von Karman constant retrieved from CASES-97 dataset using a variational method, Atm. Chem. and Phys. 8, 7045-7053 (2008)

4. W. Rankine, W. Froude, On the mechanical principles of the action of propellers, Transactions of the Institution of Naval Architects, 6, 13-39 (1865)

5. L. Prandtl, Applications of modern hydrodynamics to aeronautics, Translated by the NACA, Technical Report №116, NACA Annual Report 7, 157-215 (2003)

6. R. Wilson, P. Lissaman, Applied aerodynamics of wind power machines, National Science Foundation, Oregon State University, USA, 109 (1974)

7. J. Anderson, Fundamentals of aerodynamics, (McGraw-Hill Inc., 1991)

8. M. Hansen, Aerodynamics of wind turbines - Third edition, (Taylor \&Francis Group, 2015)

9. P. Jamieson, Innovation in wind turbine design, 297 (John Wiley \& Sons Ltd., 2011)

10. K. Cox, A. Echtermeyer, Structural design and analysis of a 10MW wind turbine blade, Energy Procedia, 24, 194-201 (2012)

11. J. Conway, Analytical solutions for the actuator disc with variable radial distribution of load, J. Fluid Mech., 297, 327-355 (1995)

12. J. Conway, Exact actuator disk solutions for nonuniform heavy loading and slipstream contraction, J. Fluid Mech., 356, 235-267 (1998)
13. T. Wang, Unsteady aerodynamic modelling of horizontal axis wind turbine performance, $\mathrm{PhD}$ Dissertation, University of Glasgow, 299 (1999)

14. R. Bontempo, The nonlinear actuator disk method as applied to open and ducted rotors, PhD Dissertation, University of Naples Federico II, 153 (2014)

15. T. Sant, Improving BEM-based aerodynamic models in wind turbine design codes, $\mathrm{PhD}$ Dissertation, Delft University - Wind Energy Institute, 447 (2007)

16. A. Miller et al., Review of Computer-Aided Numerical Simulation in Wind Energy, Renewable \& Sustainable Energy Reviews, 25, 122-134 (2013)

17. M. Buhl, A. Manjock, A comparison of wind turbine aeroelastic codes used for certification, NREL/CP500-39113, 15 (2006)

18. M. Sprague, J. Jonkman, B. Jonkman, FAST modular wind turbine CAE tool: Nonmatching spatial and temporal meshes, SciTech 2014 National Harbor, Maryland Jan. 13-17, 2014, 25, (2014)

19. M. Sprague, J. Jonkman, B. Jonkman, FAST modular framework for wind turbine simulation: New algorithms and numerical examples, AIAA SciTech 2015: 33rd Wind Energy Symposium, Kissimmee, Florida Jan. 5-9, 2015, 26 (2015)

20. J. Jonkman, FAST open-sources platform for wind turbine multy - physics engineering modeling, NAWEA Symposium 2017, 68 (2017)

21. B. Jonkman, L. Kilcher, TurbSim User's Guide: Version 1.06.00, NREL, U.S. Department of Energy, 97 (2012)

22. G. Bir, User's Guide to MBC3 (Multi-blade coordinate transformation utility for 3-bladed wind turbines), National Renewable Energy Laboratory, 19 (2008)

23. T. Larsen, A. Hansen, How 2 HAWC2, the user's manual, Risø-R-1597(ver. 4-6) (EN), TU of Denmark Roskilde, Denmark, 113 (2015)

24. T. McCoy, Advanced methods for development of wind turbine models for control design, XCEL RDF Project CWO2, Global Energy Concepts, LLC, 50 (2003)

25. Cv. Velkova, J. Minchev, Numerical flow simulation of a SCREW propeller, Machines Mechanics, ISSN 0861-9727, 118, 1-7 (2017)

26. S. Ning, et al., Development and validation of a new blade element momentum Skewed-Wake model within AeroDyn, AIAA Science and Technology Forum and Exposition, 2015 Kissimmee, Florida, 19 (2015)

27. J. Jonkman, S. Butterfield, W. Musial, G. Scott, Definition of a 5-MW reference wind turbine for offshore system development, Technical Report NREL/TP-500-38060, 75 (2009) 